\title{
Glosas bibliográficas
}

Tos libros que del maestro Sanín Cano poseíamos hasta ahora, habian sido casi todos ellos recopilados de ensayos ya publicados que sus admiradores recogieron en volumen, algunos de los cuales están hoy totalmente agotados o poco menos. Así Civilización manual (1925), Indagaciones e imágenes (1927), Divagaciones filo-sóficas y apólogos literarios (1934), muy difíciles de encontrar en el mercado, para no decir nada de su primer libro, Administración Reyes (1909) y del segundo, Elementary Spanish Grammar, publicada por las prensas de la Universidad de Oxford en 1918, que muy pocos hemos podido consultar por constituir ya rarezas bibliográficas. De Critica y Arte (1932), Letras colombianas (1935) y Ensayos (1946), aun pueden conseguirse ejemplares, pero empiezan a escasear también. Tenemos noticia de que el crítico argentino, Antonio Aita, muy devoto de Sanín Cano, preparaba desde hace un año la publicación en Buenos Aires de otra selección de ensayos, pero ignoramos si ha aparecido.

Lamentemos una vez más que en Colombia no se haya recogido en edición cuidada, si no la totalidad de los escritos del maestro, por lo menos lo más granado de lo mucho que hasta ahora ha producido. Para ello se necesitarían por lo menos quince o veinte volúmenes y no es probable que ninguna casa editora se aventure en tan riesgosa empresa sin el apoyo económico oficial. En esta misma Revista y en otras publicaciones hemos damandado reiteradamente muchos de los admiradores de Sanín Cano que el gobierno de aquel país patrocine este empeño cultural que tanto honraría a Colombia, y del cual tanto se beneficiaría nuestra cultura; mas los señores arcontes bogotanos han escuchado el clamor con oídos de mercader 
hasta ahora - tanto la administración "liberal" de don Eduardo Santos como la presente conservadora de Ospina Pérez. El maestro nunca se ha preocupado de reunir sus ensayos, ni siquiera conserva copia de ellos manuscrita ni impresa; pero su consejo y el auxilio de su prodigiosa memoria son indispensables para recopilar sus valiosísimas colaboraciones en gran número de revistas y periódicos de América y Europa a lo largo de setenta años de fecunda y ejemplar labor. Sus muchos admiradores y amigos colombianos debieran procurar que aquel gobierno auspiciara económicamente la recolección y publicación de tan valiosa cosecha. No hace muchos años el gobierno colombiano propició la publicación de una larga y costosa colección en la que se incluyeron, junto con algunos títulos valiosos que bien merecian reproducirse, unos treinta o cuarenta volúmenes de poesía chirle, una larguísima serie de apelmazados sermones que ya nadie lee ni a nadie interesan porque nada significan para el lector de hoy, muchos articulos de intrascendente costumbrismo, sin arte y $\sin$ hondura psicológica ni social, $y$ otras modalidades literarias igualmente caducas y carentes de interés para el lector actual. La obra de Sanín Cano, sin embargo, tan saturada de modernidad y de ideas, tan vigente y orientadora, tan universal en sus temas como en su espíritu, no ha merecido el honor otorgado a aquellos decrépitos géneros, no obstante que las mentes más ilustres del mundo hispano y aun de otros países han apoyado la idea de recopilarla...

Este volumen que ahora nos da el maestro Sanín Cano ${ }^{1}$ difiere de todos los anteriores que con su nombre se han publicado en el hecho de que es un libro orgánico - el primero de esta indole que ha escrito. No es ésta una autobiografía ni siquiera un libro de memorias, aunque a ambos se aproxime y de las características de ambos participe hasta cierto punto. Los dos primeros capitulos del libro - "Infancia" y "Mi carrera de maestro" - son de indole autobiográfica, pero los treinta y tres restantes, si se les considera en conjunto, son en realidad inclasificables. Algunos dan la impresión de un reportaje de altura, mas otros recuerdan los libros de memorias, las crónicas de viaje, el ensayo paisajista y lírico, la semblanza psicológica, y aun los hay de crítica literaria. Tanto mejor. La multiplicidad de temas y la diversa manera de enfocarlos, añaden variedad e interés al libro sin restarle unidad y cohesión. La personalidad del maestro, su originalisima manera de tratar los temas, su estilo 
tan rico y personal, su humor de fina calidad, concatenan esta obra y le imprimen coherencia y continuidad.

Una lectura poco atenta de este volumen dejaría la impresión de que en él Sanín Cano escribe al margen de sí mismo - de todo y de todos. Sólo en los dos primeros capítulos, tema y narrador se identifican: la adolescencia y la juventud de uno devienen objeto directo del relator. En todos los restantes capítulos, la vida y la personalidad del autor pasan a un segundo plano y quedan aparentemente preteridas $u$ olvidadas. En realidad no ocurre así más que en la intención del autor. Porque como el propio Sanín Cano ha dicho, el autor nunca puede evadirse o preterirse del todo de su obra por más que en ello se empeñe. La producción del maestro colombiano constituye el mejor empleo que en castellano pudiera aducirse para confirmar esta tesis. Lo mismo en este libro que en toda su obra escrita, se nota un reiterado esfuerzo consciente por eliminarse él mismo, un flaubertiano afán de objetividad - de impersonalidad casi. Rarísima vez encontraremos en los escritos de Sanín Cano el pronombre "yo" o una desinencia verbal en primera persona de singular. Esto que en la modalidad estilística del maestro es una característica definidora de su aspiración a la serena imparcialidad frente a los problemas que dilucida, es también un arte difícil de cultivar, máxime en los géneros crítica y ensayo de suyo propicios a la subjetivación.

Mas pese al deseo de mantenerse en segundo plano y aparecer como simple espectador y comentarista, emocionalmente desvinculado de sus temas, la personalidad intelectual y moral del maestro se nos revela íntegra en este deleitoso libro. Cierto que los que bien le queremos y admiramos hubiéramos preferido menos rigor impersonal y más abundantes referencias a su vida por ser la que más nos interesa. Pero, repito, don Baldomero se nos da en este libro en proporción mucho mayor de lo que él mismo acaso sospechó y de lo que una lectura superficial podría descubrir.

En De mi vida y otras vidas el lector traba conocimiento con el autor indirectamente. Es a través de "otras vidas" que percibimos la suya, en forma refleja podría decirse. No recuerdo si fué Renán quien dijo que sólo debiéramos escribir de lo que amamos o sobre lo que nos es dilecto y afín. Es un principio que ha regido la fecunda labor del maestro antioqueño. De ahí el tono constructivo 
de su fecunda obra de escritor, a pesar de su congénito escepticismo y de su rico sentido de humor que le permite sonreir bondadosamente ante la estolidez humana.

Discurre Sanín Cano en este libro sobre una serie de personalidades - y algunos temas - afines con las cuales estuvo alguna vez en contacto directo o indirecto, y de cada una de ellas da una rápida y penetrante semblanza, escrita con honda simpatía intelectual o humana. Por sus páginas desfilan José Asunción Silva, Guillermo Valencia, Leopoldo Lugones, Enrique Larreta, Antonio José Restrepo y otras figuras de las letras americanas, y entre las europeas Bertrand Russell, Robert Cecil, Jorge Brandes, James FitzmauriceKelly, Remy de Gourmont, Roberto Cunninhame Graham, etc. Pero más que en el análisis de su respectiva obra literaria don Baldomero nos deja aquí la estampa humana. Más que el intelectual, al maestro le interesa ahora el hombre que en cada caso se esconde detrás del escritor. De la obra de la mayoría de los intelectuales aquí retratados ya don Baldomero había escrito muy agudos ensayos. La personalidad humana es lo que principalmente reclama su atención en este libro. Por eso muchas de estas "siluetas" vienen a ser complemento de no pocos ensayos anteriores, inspirados por la obra de los mismos autores.

A través de estos hombres y temas vamos descubriendo la intimidad del maestro, sus gustos y predilecciones, sus contactos con otras culturas, su riquísima experiencia vital, su sensibilidad, su amor a la naturaleza, a cuya observación y estudio ha consagrado luengos años. Al hablar de la moral de los hombres objeto de sus disquisiciones, se nos revela la ética personal del autor, nos percatamos de su intimo sentir y percibimos su escepticismo ante el desquiciamiento del mundo actual, sobre todo en el campo de las relaciones internacionales. Magüer su aparente impresionismo de comentador que glosa hechos y hombres, acontecimientos y sistemas, este libro está saturado de pensamientos y de hondas preocupaciones que nos invitan a reflexionar, a meditar sobre múltiples problemas. Con la serenidad en él inherente y la madurez de su larga experiencia y de su prodigioso acervo cultural, acota don Baldomero en este volumen infinito número de temas que van desde las páginas bellamente'paisajistas y los "retratos", hasta las cogitaciones filosóficas, expuestas en esa forma sencilla $y$ desprovista de dogmatismo y de 
la pedantería palabrera tan en boga hoy, que hacen de su estilo uno de los más ricos y ejemplares con que actualmente contamos.

Confiemos en que el maestro prolongará estos recuerdos en sucesivos volúmenes. Decía Sarmiento que el aspecto más valioso de nuestra literatura es el de carácter biográfico, y este libro de Sanín Cano corrobora el aserto. Aquí sólo tenemos una mínima expresión de esa inagotable mina que es el hontanar de sus recuerdos. Quieran nuestros hados que no le falten la salud y el sosiego necesarios para continuar esta labor con la que tanto se enriquecería nuestra cultura.

El "Fondo de Cultura Económica", de México, y la "Editorial Losada" de Buenos Aires, son, sin duda, las dos empresas editoriales de mayor trascendencia para nuestra cultura con que actualmente contamos. Con magnos proyectos de ambas estuvo íntimamente relacionado Pedro Henríquez U'reña, americano representativo y espíritu amplio que supo desprenderse de estrechos y distanciadores nacionalismos para propugnar una cultura de signo continental. Desdichadamente Pedro se nos fué cuando más indispensable era su rectoría, pero su obra y su benéfica influencia dejaron honda huella en nuestras letras.

Tanto el "Fondo" como "Losada" han abandonado también el nacionalismo cerrado que hasta muy recientemente caracterizaba a las editoriales americanas para dar cabida a los escritores de mayor significación de todos los países hermanos. En importantísimas y nutridas series o colecciones ya famosas, ambas casas vienen reeditando muchos de los libros más sobresalientes que en América se publicaron en el siglo xIx, precedidos de sendos estudios especializados que constituyen muy provechosas revaloraciones.

En la colección "Tierra Firme" que alcanza ya unos cincuenta volúmenes, acaba de publicar el "Fondo" un muy interesante panorama de la literatura cubana por Félix Lizaso. ${ }^{2}$ Lizaso es un ensayista y crítico dotado de vasta información y cultivado criterio literario. Como tal se reveló hace ya muchos años cuando en colaboración con José Antonio Fernández de Castro publicó una excelente antología de la poesía moderna en Cuba que es modelo en este género 
de libros en Hispanoamérica, tanto por la agudeza crítica de las estimaciones cuanto por la utilísima bibliografía que en cada caso acompaña a los poetas alli incluídos. Desde entonces, Lizaso ha publicado varios libros sobre diversos temas que representan meritorias aportaciones a la cultura cubana y americana. Ha consagrado su vida al estudio de José Martí y sus ensayos e investigaciones en torno a la vida y el pensamiento del Apóstol figuran entre los más enjundiosos y esclarecedores que en la ingente bibliografía martiniana existen. Aunque es hombre de amplia cultura, su interés ha gravitado siempre hacia la literatura vernácula y sus figuras más representativas.

Constituyen la base de este libro las conferencias que Lizaso pronunció en la Universidad de Buenos Aires en 1946, completadas ahora con dos capítulos finales sobre la evolución cultural de Cuba en la era republicana. El título es quizá excesivo porque quedan fuera del contenido del libro otras importantes manifestaciones. Lizaso enfoca el tema a través de los hombres de letras y del desarrollo de los estudios filosóficos en la isla durante el siglo XIX, pero no incluye - ni podía incluir en tan corto número de páginas- otras expresiones culturales tales como los estudios científicos, la música, las artes plásticas, etc. Más apropiado al contenido nos hubiera parecido el título "Panorama de la literatura cubana" que el que se le puso, mas es muy posible -y aun probable- que el autor no sea responsable de este detalle, de escasa trascendencia por lo demás.

Lizaso ha tratado el tema con criterio rigurosamente selectivo y en torno a unas cuantas figuras cimeras se desarrolla este panorama. De ahí que hombres como José Agustín Caballero, Félix Varela, José Antonio Saco, José de la Luz y Caballero, Domingo Delmonte, José María Heredia, Enrique José Varona y José Martí, aparezcan aqui adecuadamente tratados. Hasta 1900 éstos son, indiscutiblemente, los nombres más sobresalientes que eslabonan y dan brillo al proceso literario cubano. En torno a ellos y con ellos colaborando, aparecen otros muchos hombres de letras que el autor menciona y a veces avalora en apretada síntesis urgido por los factores tiempo y espacio.

Lizaso ha logrado darnos una rápida idea de la evolución económica de Cuba y del clima político en que se gestó la cultura de 
la isla. La preocupación patriótica condicionó $-\mathrm{y}$, en algunos casos, quizás limitó- la obra de creación y el espíritu de muchos de los hombres mejor dotados que Cuba produjo en el décimo nono. Las tres generaciones que en él florecieron, vivieron perennemente urgidas de anhelos libertarios, y a fomentar la cubanidad y el patriotismo mediante la cultura consagraron sus más tenaces esfuerzos. La literatura cubana de la centuria pasada se escribió casi toda en función de patria - como la de toda nuestra América entre 1810 y 1850. De ahí el carácter tan peculiar de las letras cubanas durante aquel periodo. Lizaso ha sabido destacar con nitida claridad este particular matiz de los literatos cubanos y ubicarlos acertadamente en su circunstancia.

De lamentar es que el autor no haya dedicado un capítulo especial a la generación nacida entre 1840 y 1865 , es decir, la que podriamos llamar la generación de Martí, o sea la que va a dar su obra más granada entre 1880 y 1910. Fué ésta una promoción literaria que ningún país hispanoamericano superó en los géneros didáctica, crítica literaria, estudios filosóficos y político-sociales en aquellos tres decenios. De ella sólo se estudian en este panorama las dos figuras máximas - Martí y Varona. A los demás sólo se les alude rápidamente, $\mathrm{y}$ en tácito reconocimiento quedaron no pocos nombres cimeros que dieron lustre a la cultura cubana en la consabida treintena. Martí y Varona no constituyen epígonos aislados y solitarios. Son más bien primus inter pares. Junto a ellos y con ellos colaborando, unos desde Nueva York, otros desde París, Madrid, México o Bogotá, y los demás en el ambiente vernáculo, encontramos un notable grupo de grandes prosistas y algunos poetas, todos imbuidos de un espíritu universalista y filosófico, que ni antes ni después ha sido superado en Cuba. Entre los más destacados habría que recordar a Manuel Sanguily, Rafael Montoro, Manuel de la Cruz, Rafael María Merchán, Aurelio Mitján, Enrique Piñeyro, Eliseo Giberga, Emilio Bobadilla (Fray Candil), José de Armas (Justo de Lara), Nicolás Heredia, Domingo Figarola-Caneda, Mariano Aramburo, Manuel Márquez Sterling, José A. González Lanuza, Antonio S. de Bustamante, José A. Rodriguez García, etc., y los poetas Carlos Pío y Federico Urbach, Julián del Casal, Juana Borrero, María Luisa Pérez de Zambrana y Bonifacio Byrne, que con Martí y Varona forman la última generación surgida en el clima 
colonial. No todos ellos comulgaron en los ideales independentistas ni compartieron el mismo credo filosófico, pero a todos los unía el empeño cultural y el ansia de una cubanidad acrisolada y digna. Confiemos en que en futuras ediciones del libro repare Lizaso la injusta preterición.

Lo mismo podría decirse en lo que atañe a la generación siguiente, la llamada generación de "Cuba Contemporánea" por haber sido esta revista la que congregó a la mayoría de sus integrantes. Esta generación presenta más de una tangencia con la anterior y como su antecedente es acreedora a más detenido estudio y atención de los que en este Panorama se le consagran. No pocos de los componentes de esta primera promoción surgida bajo Cuba republicana dan continuidad a la ideología patriótica sustentada por la precedente y en ellos se prolonga la preferencia por el ensayo en prosa, siempre veteado de honda preocupación cívica - aun cuando escriban sobre temas abstractos y al parecer distantes. Hombres como Fernando Ortiz, Carlos de Velasco, José Sixto de Sola, Jesús Castellanos, José Antonio Ramos, Medardo Vitier, Fernando Iles, Max Henríquez Ureña, Alfonso Hernández Catá, Carlos Loveira, Francisco González del Valle, Ricardo Sarabaza, Emilio Gaspar Rodríguez, Ramiro Guerra, Luis Rodríguez Embil, Luis Felipe Rodríguez, Miguel de Carrión, Emilio Roig y, un poco más recientemente, Francisco José Castellanos, fueron los herederos y continuadores de los grandes prosistas finiseculares y como ellos cultivaron el ensayo filosófico, histórico, sociológico, político o de crítica literaria. Pero a diferencia de sus antecesores, carecen por lo general del espíritu universalista y del enciclopedismo que éstos poseian. Es también una generación de autodidactas que carece de la disciplina académica y de la sólida base humanística que caracterizaban a la última parvada colonial. Aunque parezca insólito y hasta un contrasentido, estos intelectuales que escriben en Cuba "libre" entre 1910 y 1930, están más urgidos de angustia patriótica que los que los precedieron. Su ethos es más transido y agónico que el que privó entre los hombres del 95 hasta 1900. Otra diferencia entre estas dos generaciones limítrofes es que la última, si bien no alcanza la prestancia de los grandes prosistas que la precedieron, en cambio los supera en los géneros novela y cuento. Hasta su advenimiento, estas dos formas de creación se habían cultivado en Cuba esporádi- 
camente por individuos aislados y sin continuidad concatenada, como la poesía, por ejemplo. Ahora, por el contrario, constituyen una manifestación generacional. Por primera vez en la historia literaria de Cuba surge un grupo de novelistas y cuentistas de cierto rango que va, no sólo a superar cuanto en ambos géneros se había hecho hasta entonces, sino a prestigiarlos. Los nombres de Hernández Catá, Jesús Castellanos, Carlos Loveira, José Antonio Ramos, Miguel de Carrión, Luis Felipe Rodríguez y otros de menor cuantía figurarán con gloria entre los que redimieron a la novela y al cuento cubanos del marasmo en que habían caído tras el acierto con que los había iniciado Cirilo Villaverde en la primera mitad del siglo anterior. La poesía, en cambio, decae y apenas se salva con tres poetas de cjerta talla: Agustín Acosta, Regino E. Boti y José Manuel Poveda. Fué ésta una generación en parte frustrada y trágica, como luego se verá. Tuvo que luchar contra la indiferencia, la "guarangueria" y la estolidez del ambiente, $y$ unos seis $u$ ocho de sus componentes mejor dotados murieron antes de madurar.

Hay un punto de incidencia, sin embargo, en el que el sentir de las dos generaciones se funde y una no hace más que prolongar -intensificándolo- el sentido de frustración patriótica de la otra. La mayoría de los escritores finiseculares que sobrevieron a la implantación de la república (1902), se tornaron escépticos y murieron oprimidos por irreductible pesimismo. Asi Montero, Giberga, Piñeyro, Merchán, Armas, Aramburo, Heredia, Sanguily, FigarolaCaneda y el propio Varona. Por las mismas razones, agudizadas en el transcurso de los años, la generación de "Cuba Contemporánea" surgió ya larvada de este sense of frustration que se acentuará en la misma medida en que las motivaciones que lo provocaron se agravan. Por una parte, la Enmienda Platt, impuesta por los Estados Unidos a Cuba $a b$ initio, la convirtió en dependencia política de Washington y en factoria económica de Wall Street; por la otra, la relajada conducta cívica de los cubanos que usufructuaron el poder durante el primer cuarto de siglo a partir de 1902, sumieron a esta joven promoción en el desaliento, y el pesimismo. De ahí el pathos ágónico que la caracteriza.

Comóel de las tres anteriores, el quehacer generacional de la primera surgida en la etapa independiente, fué propiciar el desarrollo de una cubanidad depurada de vicios y cortapisas. Pero mientras 
las tres generaciones anteriores fueron optimistas - hasta 1900porque luchaban por un ideal que nunca alcanzaron y por ende no pudieron descorazonarse, ésta de ahora tuvo que enfrentarse con lo que uno de sus más talentosos exponentes llamó "Las impurezas de la realidad", título de una de las novelas de más transido análisis del ambiente político-social cubano hacia 1920. De ahí la angustia patriótica y la proclividad satírica y docente que limitan la obra de estos hombres. Por fortuna para Cuba, la sangrienta dictadura machadista, al agudizar las lacras políticas y llevar el entreguismo a los Estados Unidos a sus extremos más corruptores y perniciosos, provocó una reacción saludable que si bien se revistió de tonos violentos en algunos sectores, en general fué optimista y esperanzada. Esta última generación que a falta de mejor nombre se ha llamado "vanguardista", se caracteriza por su espíritu iconoclasta, revisionista y crítico. Es demasiado prematuro todavía aventurar juicio sobre ella.

En las literaturas de Cuba y Venezuela pueden descubrirse varios puntos de contacto o similitudes. Entre otros, uno de los más curiosos es el hecho de que ambas se producen en el exilio. Claro que en muchos paises hermanos podrían encontrarse escritores desterrados, pero el único que se asemeja en esto a las dos literaturas precitadas es la Argentina durante los veinte años que duró la dictadura de Juan Manuel de Rosas. Pero mientras esto fué la excepción transitoria en la república del Plata, en los casos de Cuba durante todo el siglo xIx y de Venezuela hasta el presente, constituye una constante y un elemento definidor. Así como en la Gran Antilla sus más destacados pensadores y poetas escriben desde el extranjero comenzando ya con Heredia y Varela en 1923 hasta el advenimiento de la independencia, de la misma manera las figuras más sobresalientes del intelecto venezolano, desde Andrés Bello hasta Rómulo Gallegos, Mariano Picón Salas, Andrés Eloy Blanco y Arturo Uslar Pietri, pasando por Rafael María Baralt, José Antonio Pérez Bonalde, Nicanor Bolet Peraza, César Zumeta, Rufino Blanco Fombona, José Rafael Pocaterra, Pedro Emilio Coll, Teresa de la Parra y otros muchos, todos, por una razón o por 
otra, escribieron en el ostracismo político - la mayoría- y más o menos voluntario; algunos. En el momento presente, la dictadura militar que dió al traste con el más noble y honrado empeño reivindicador $y$ renovador iniciado en aquel pais hasta ahora, ha lanzado de nuevo al exilio a los hombres más representativos de su cultura, sin contar con los muchos a quienes no se les ha permitido expatriarse.

Hasta 1925, la literatura vehezolana había producido vigorosas figuras aisladas como las ya aludidas $\mathbf{y}$ otras tales como Cecilio Acosta, Gil Fortoul, Manuel Díaz Rodríguez, etc., pero en ningún momento encontramos un grupo de escritores suficientemente numeroso, afines en el espíritu y la comunidad de intereses que merezca el nombre de generación. E1 "quehacer generacional" que da la tónica a las promociones literarias, no se descubre allí nítidamente antes de la fecha dicha. Hasta entonces, Venezuela es el país de los grandes epígonos, de las figuras cimeras - lo mismo en la historia que en las letras- pero de un bajo nivel cultural medio. Sus grandes hombres se han dado a contrapelo y a pesar del ambiente impropicio, más bien como reacción contra la chatura intelectual media que impulsados por la atmósfera colectiva. Fué entre 1925 y 1940 cuando apareció en Caracas la primera generación literaria digna del nombre, con aspiraciones y propósitos colectivos, con ideales y tareas comunes a sus componentes, y vertebrados por un agudo sentido generacional. La muerte del feroz Juan Vicente Gómez, en 1935, desató las potencias creadoras de la juventud y galvanizó sus anhelos reivindicadores, de la misma manera que su criminal dictadura la había aunado en el ansia de libertad y renovación en todos los órdenes. Es todavía prematuro aventurar juicio definitivo sobre esta pléyade de jóvenes poetas, novelistas, cuentistas, ensayistas, dramaturgos y críticos que en aquellos quince años empezaron a dar frutos granados. Todos ellos recién comíenzan a madurar y acaso ninguno haya dado todavía su obra de más perdurable aliento. Lo que si puede afirmarse sin temor a penosas rectificaciones es que en el último cuarto de siglo ha cristalizado en Venezuela un ambiente intelectual, una común aspiración superadora, y una conciencia generacional que no se habían dado allí antes. Este impulso renovador y los hombres que más dignamente lo encarnan, han producido ya una larga serie de libros en todos los géneros - muy 
particularmente en la novela, el ensayo, la poesia, el cuento y el teatro- que con la posible excepción de Gallegos en la novela, supera cuanto hasta ahora se había hecho. Anima a esta genęración un dramático espíritu revisionista, intensamente nacionalista y patriótico, que busca transido el carácter definidor del país y procura encauzarlo por rumbos democráticos y progresistas. Pero si a todos anima la preocupación por la venezolanidad, esto no obsta ni obstruye su anhelo universalista. Nunca antes se había procurado fundir lo vernacular y lo universal con más aguda conciencia.

Una de las figuras más destacadas de esta promoción que hoy anda entre los cuarenta y los cincuenta y cinco años, más o menos, es Arturo Uslar Pietri, ya sobradamente conocido en nuestra América. El libro que lo reveló - fuera de las fronteras nativas- como novelista de talla y buen conocedor de la historia venezolana, fué Las lanzas coloradas, aparecido en 1931. Recientemente ha publicado otra novela, El camino de "El Dorado" (1948) que supera a la anterior y cuenta entre las novelas mejor calibradas que en el país se han producido. Pero Uslar Pietri, como ese otro gran coetáneo y compatriota suyo, Mariano Picón Salas, además de novelista, es un ensayista histórico-sociológico de muy fina calidad y un excelente crítico literario, además. En el libro que aquí se acota ${ }^{3}$ demostró Uslar Pietri sus aptitudes de pensador y de crítico, tanto como de prosador hábil.

A semejanza del Panorama de Félix Lizaso que antes se comentó, este libro de Uslar Pietri tuvo su génesis en una serie de conferencias que el autor dictó en Columbia University en el verano de 1947. Letras y hombres de Venezuela es más un intento de interpretación del espíritu venezolano a través de sus figuras culminantes que un panorama de su evolución literaria como el de Lizaso. En estas páginas predomina el ensayista sobre el historiador literario, el sentido de análisis esclarecedor sobre la intención docente, la interrogación angustiada sobre la exposición. Es ésta una larga y jugosa disquisición en busca de la venezolanidad. ¿Qué es lo que caracteriza a Venezuela a lo largo de su historia? ¿Cómo definir su espiritu? ¿En qué se diferencia el venezolano de sus hermanos del continente? ¿Cómo se ha manifestado su idiosincrasia en la literatura? En estas 175 páginas Uslar Pietri intenta interpretar estos temas y dar respuesta a éstas y otras muchas interrogaciones que 
él mismo se formula. Para ello empieza por darnos una aguda exégesis del perfil histórico del país hasta el advenimiento de la era revolucionaria en dos penetrantes capítulos: "La invención de Venezuela" y "Las luces en Tierra Firme". En ellos describe de modo suscinto pero certero la base económica de la vida venezolana y su organización hasta fines del siglo xvirr. Ya en la página 15 nos adelanta en ceñida definición, las peculiaridades del venezolano en estas palabras que luego elaborará ampliamente: "Es el alma del mestizo la que va a darle su psicología a la nación y a caracterizar su historia. Atormentada por sus dos pasiones fundamentales: la igualdad y el mesianismo". Luego en la página 58, al interpretar y resumir el efecto de la epopeya bolivariana sobre el alma de Venezuela, reiterará este concepto: "Las dos pasiones fundamentales del alma popular venezolana: el mesianismo y la igualdad, quedan vivas $\mathrm{y}$ ansiosas trabajando su historia.

"Bolivar lo ha hecho, para siempre, un pueblo hambriento de grandeza".

Además de los dos capítulos iniciales ya aludidos, el libro contiene otros nueve en los que se estudian los siguientes temas: III "Bolívar"; IV "Andrés Bello, el desterrado"; V "Juan Vicente González, el atormentado"; VI "Cecilio Acosta y la gentil libertad"; VII "Pérez Bonalde, el poeta"; VIII "Tío Tígre y Juan Bobo"; IX "La novela venezolana"; $\mathrm{X}$ "El testimonio de Teresa de la Parra" y XI "El cuento venezolano". Sirve de complemento a estos temas una muy útil bibliografía selecta.

Como se ve por el indice transcrito, Uslar Pietri no se ha propuesto darnos un epítome o sinopsis de la historia literaria de su país sino una interpretación del espíritu nacional según se manifiesta en sus hombres más representativos y en los géneros literarios más cultivados. Por todo el libro se percibe este transido afán definitorio.

Los sendos capítulos que el autor consagra a la novela y al cuento, son de gran interés por constituir una apretada síntesis de la evolución de los dos géneros tanto como por la calidad de las valoraciones. Algunos de los juicios de Uslar Pietri acaso no sean universalmente compartidos en los países hispánicos. Tales las afirmaciones con que se inicia el capítulo sobre la novela. Pero exceptuando estas discutibles generalizaciones, hay que reconocer la exce- 
lencia y hondura de sus conclusiones, lo mismo en lo atañadero a los valores individuales que en lo referente a las características que definen la venezolanidad.

La variante dialectal del idioma español que el gaucho desarrolló durante los siglos xvirI y xix, nunca adquirió fijeza definitiva ni regularidad y norma, sino que se mantuvo siempre en un estado de fluidez muy elástica y hasta un poco caótica, así como de compleja pluralidad fonética para muchos vocablos. Ni los gauchos más o menos cantores ni los payadores auténticos escribieron nunca sus cielitos, gatos, chacareras, triunfos, malambos y vidalas, ni mucho menos las payadas en que competían y medían su capacidad imaginativa y poética los trovadores pampeanos. El mismo Santos Vega, el más afamado de todos - si en realidad existió como creen Bartolomé Mitre y Ricardo Rojas- probablemente no sabía leer ni escribir. De hecho no se conserva una sola muestra de la poesía gaucha popular ni del mester payadoresco que haya llegado manuscrita hasta nosotros. Todo el acervo poético gauchesco que se ha rescatado del olvido mediante la escritura ha sido recopilado por los eruditos en la tradición oral o es obra de ingenios cultos, como "El amor de la estanciera", el "Romance de Zeballos" y las producciones que en formas gauchescas escribieron Bartolomé Hidalgo, Juan Gualberto Godoy y sus continuadores todos. Es posible que ya desde antes de Juán Baltasar Maciel y Pantaleón Rivarola, algún pedestre versificador urbano del siglo xvirr cultivara el género y escribiera sus imitaciones de la agreste musa pampeana, como ocurrió con las dos composiciones precitadas, de autor desconocido. Mas lo único indubitable es que los cantores gauchos y payadores legítimos jamás escribieron sus improvisaciones por la sencilla razón de que no conocían el alfabeto y, por consiguiente, su caudal poético original y popular se transmitió siempre por tradición oral.

Al decir esto me refiero al gaucho propiamente pampeano bonaerense $\mathrm{y}$ sántafecino. Los gauchos que habitaban de Córdova y San Juan para el norte eran mucho más evolucionados y por ende nás cultos porque se mantuvieron en contacto estrecho con la población urbana de aquellas provincias. Es probable que entre éstos 
hubiera algunos capaces de escribir sus improvisaciones. Mas el gaucho que desarrolló las formas de vida y de economía más originales $\mathrm{y}$ primitivas $\mathrm{y}$, por lo tanto, dió la tónica cultural $\mathrm{y}$ poética más autóctona, fué el que habitaba las provincias del litoral pampeano. Fué el primero que se formó y el que se mantuvo más aislado de la civilización. Por eso su agreste musa resultó más rústica, diferenciada y genuina.

La prosodia o fonética gauchesca variaba mucho por las razones apuntadas. En los estudios de gauchología nunca se han ubicado estas variantes en la topografía argentina ni es probable que puedan fijarse ya porque el original humano desapareció hace muchos años. Si en la época de Rosas, por ejemplo, que señala el momento de apogeo y máxima influencia del gaucho en las formas de vida $y$ en el lenguaje urbanos, algún filólogo o fonetista se hubiese preocupado de estudiar seriamente el tema y de recoger sobre el terreno en las diferentes regiones la tradición poética gauchesca, es probable que se hubiesen podido deslindar dichas variantes y localizar acentuadas diferencias fonéticas. Si tal se hubiera hecho, habría sido fácil fijar con cierta precisión las variantes prosódicas que se estilaban en diversos pagos, lo mismo que las discrepancias que probablemente existían entre la poesia propiamente payadoresca $y$ la popular de los improvisadores menores que seguramente seguían más de cerca y más fielmente la fabla vernácula del gauchaje común. Mas esto no se hizo en aquella época ni antes de que el gaucho se extinguiera y hoy es de todo punto imposible restaurar o fijar de manera científica la peculiar y complejísima modalidad prosódica de $\tan$ interesante personaje por carecer de documentos escritos auténticos.

Ya desde antes de la independencia, tanto el gaucho como su expresión lingüística empezaron a "mesturarse" con las formas de vida, las costumbres y el lenguaje urbanos. Esta hibridación y rèciproca influencia entre el "pueblerino" y el gauchaje aumentó durante las guerras de la independencia y en el período de las montoneras que en cierto modo se prolonga hasta la caída de Rosas. A partir de este instante, el gaucho degenera y el mestizaje lingüístico se acentúa aún más, tanto en la Pampa como en la urbe porteña debido al influjo del "gringo" que a partir de la organización nacional (1862), las invade en verdaderas avalanchas. Este proceso 
se precipita en forma acelerada y fatal para el gaucho bajo las tres administraciones que siguieron a la de Mitre: las de Sarmiento, Avellaneda y Julio Roca (1868-1886).

Aun podría citarse otro factor que contribuyó en no escasa medida al confusionismo lingüístico gauchesco y a la desorientación de no pocos escritores que lo han remedado y hasta en algunos estudiosos que durante los últimos treinta o cuarenta años se han propuesto dilucidar el tema y deslindar los campos para dar cierta fijeza morfológica al lenguaje del gaucho. Durante los dieciocho años precitados y los que siguieron hasta la vuelta del siglo, Buenos Aires recibió un torrente inmigratorio tan enorme, tan heterogéneo e inculto, que corrió un serio peligro de convertirse en una nueva Babel. Italianos, polacos, judíos de muchas procedencias, alemanes, franceses, ingleses, vascos, catalanes, irlandeses, etc., invadieron esta nueva Babilonia por centenares de miles. Con el prodigioso incremento demográfico coincidieron el no menos asombroso desarrollo cconómico de la capital y la inevitable corrupción política y social que acompaña siempre a estos periodos de fabulosa riqueza improvisada. El aluvión inmigratorio fué demasiado grande y repentino para que la incipiente cultura argentina y su escasa población pudieran asimilarlo e incorporarlo a su propia tradición cultural. Fué en ese período cuando los elementos maleantes y criminosos de los barrios bajos porteños desarrollaron su propia jerga o lunfardo. Dichos arrabales constituían la frontera en que se fundieron muchos elementos gauchescos desplazados de sus pagos por la injusticia y la persecución de que eran víctimas y la población delincuente porteña compuesta en gran parte de inmigrantes analfabetos. Esta fusión étnica dió origen al tipo social llamado "compadrito" y a su peculiarísima expresión lingüística o caló —el lunfardo- que muchos han confundido con las formas dialectales gauchescas. $\mathrm{Ni}$ el "compadrito" tiene nada que ver con el gaucho, aunque presente algunas afinidades con el "malevo", ni el lunfardo se relaciona con la forma dialectal que el gàucho empleó, la cual es de pura cepa española, si bien enriquecida con el aporte de las lenguas indígenas. Ambos -el "compadrito" y el lunfardo- son fenómenos exclusivamente urbanos y posteriores al desarrollo de las expresiones culturales gauchescas, pero han servido para confundir a muchos escritores que del tema han tratado. 
José Hernández fué, sin duda, el escritor que más amó al gaucho y el que mejor le conoció. Es también, de todos los poetas cultos que escribieron en formas dialectales, el que mejor asimiló su modalidad lingüistica y fonética por haber vivido unos cuarenta años entre el gauchaje. Sin embargo, el propio Hernández, no obstante su íntima familiaridad con este personaje y con su expresión prosódica, distaba mucho de estar seguro de su ortografía cuando escribió el Martín Fierro. Un cuidadoso cotejo de sus manuscritos con las correcciones que introdujo en las sucesivas ediciones que pudo vigilar y con las añadidas al ejemplar corregido que se conserva en el Museo Mitre, revela los titubeos del autor en cuanto a la prosodia de muchos vocablos y a la grafía que para representarlos debía emplear.

El lector me perdonará estar tardía alusión a un libro relacionado con el tema aquí tratado, aparecido hace ya un lustro, pero que yo no habia tenido oportunidad de leer hasta muy recientemente: Martín Fierro, Edición crítica de Carlos Alberto Leumann, Buenos Aires, Angel Estrada y Cía., S. A., 1945 - 599 páginas. El esfuerzo realizado por el señor Leumann bien merece un comentario - maguer volandero y moroso- siquiera sea para dar fe de su existencia ya que fuera de la Argentina apenas se le conoce.

Carlos Alberto Leumann aparece haber sido el primero - $y$ acaso el único hasta ahora- de los escritores y críticos argentinos que ha logrado examinar el manuscrito de la segunda parte del poema titulada La vuelta de Martín Fierro que se suponia perdido. Secuela de este privilegio fué la edición crítica mentada y otro libro del mismo autor titulado El poeta creador, cómo hizo Hernández "La vuelta de Martín Fierro", (282 páginas), publicado por la Editorial Sudamericana, de Buenos Aires, en el mismo año de 1945. Sólo haré aquí una breve referencia a este fervoroso tributo o verdadera exaltación del genio creador de Hernández. Muchos de los conceptos contenidos en este libro se repiten en el extenso prefacio de la edición crítica o en las noventa páginas de notas y comentarios que sirven de epílogo al texto. En El poeta creador, el señor Leumann, con el manuscrito a la vista, hace el análisis del poema y nos da su entusiasta interpretación del mismo. Por la vehemencia y fervor patriótico que caracterizan sus comentarios, hay que afiliar al señor Leumann a la escuela de Leopoldo Lugones y de Ricardo 
Rojas que de la poesía gauchesca y del Martin Fierro han hecho banderia de nacionalismo literario. Una actitud más serena y menos exaltada habría beneficiado este estudio y le habria dado carácter más científico y severo. En torno a Martín Fierro se ha desarrollado en la Argentina una especie de mística de proclividad nacionalista y patriotera, particularmente entre los continuadores de Lugones y Rojas, que le resta objetividad y sentido de proporción a estos estudios. De tal defecto adolece este libro del señor Leumann y también muchos de los comentarios que preceden y epilogan el texto de su edición crítica. Para el lector distante, horro de prejuicios nacionalistas, algunas de las conclusiones del señor Leumann son discutibles.

En la susodicha edición crítica, el señor Leumann se propuso, ante todo, restaurar el texto del poema a su pureza original y corregir los errores ortográficos que en él se han introducido por diferentes editores $\mathrm{y}$ correctores $\mathrm{y}$ hasta por el propio autor. Dificil sería encontrar un libro escrito en los últimos cien años en lengua española en el que mayor número de variantes gráficas se hayan introducido que el Martín Fierro. El primero que incurrió en esta veleidad o inconstancia fué Hernández mismo en sucesivas ediciones. Luego los infinitos editores que el poema ha sufrido, se creyeron autorizados a enmendarle la plana, unas veces por ignorancia, otras por petulante mania academicista. Como Cervantes, Hernández ha sido considerado por muchos como ingenio lego, poco versado en materia poética y despreocupado en demasía. No se ha tenido en cuenta la advertencia del poeta de que muchos errores aparentes de su obra se deben al realismo crudo y a la aspiración a la copia exacta del original y no a desconocimiento de las reglas del arte. En este prurito rectificador ha caído el mismo señor Leumann que a veces se toma libertades discutibles con el texto en su empeño de devolverle su prístina pureza. Como ya antes se apuntó, hoy es en extremo difícil restaurar o fijar la grafía gauchesca, máxime después del caos que han introducido muchos editores del poema hernandiano. Si se cotejaran las muchas ediciones más o menos cuidadas que de este libro existen, tales como las vigiladas por Martínez Estrada, Ricardo Rojas, Eleuterio F. Tiscornia, Santiago M. Lugones, José Ingenieros, ésta del señor Leumann y tantas otras, podrian descubrirse múltiples variantes. El señor Leumann ha te- 
nido la ventaja $-\mathrm{y}$ el privilegio- sobre todos los editores anteriores, de tener el manuscrito de la mayor parte de "La Vuelta" a la vista y sobre él ha procurado basar ésta que él considera edición definitiva. (He dicho "la mayor parte" porque no se conserva -o por lo menos no se ha encontrado todavía - el manuscrito de la payada con el negro ni el de los últimos tres cantos). Para realizar su trabajo, el autor, según propia confesión, no se ha limitado a la exacta reproducción del manuscrito recién descubierto y de las correcciones hechas por el poeta al texto de la "Ida" o primera parte, sino que ha tomado en cuenta las primeras ediciones del poema $y$ otros documentos y aun el "testimonio de viejos paisanos". No pretende esta nota otra cosa más que llamar la atención de los profesionales de nuestra literatura sobre la existencia de esta hermosa edición de la casa Estrada y señalar el plausible esfuerzo realizado por el señor Leumann. Ni aquí se dispone de espacio para más dilatado examen ni el que escribe está equipado con la indispensable preparación filológica en materia gauchesca para enjuiciar técnicamente la labor realizada por el señor Leumann.

Una omisión - una injusta preterición- es particularmente notable en este libro. Tanto en las ciento cincuenta páginas de comentarios que anteceden al texto como en las noventa de notas y aclaraciones que lo siguen, el señor Leumann menciona por su nombre a muchos comentaristas menores y no pocas ediciones más o menos cuidadas. Sin embargo omite mencionar el nombre del más importante de todos los filólogos que han estudiado la lengua de Martín Fierro y que en 1925 nos dió una edición crítica muy valiosa - cualesquiera que sean las máculas o defectos que puedan señalarse en ella-y en 1930 publicó el estudio más serio que hasta ahora tenemos del lenguaje martinfierrista, además de otras ediciones y estudios muy estimables: Eleuterio F. Tiscornia. Tampoco se cita ni bajo el nombre del autor ni del editor la consabida edición de 1925, si bien se la alude veladamente muchas veces, y frecuentemente con intención peyorativa. Esto es injusto. El señor Tiscornia era uno de los pocos filólogos con preparación académica seria que se han preocupado del tema gauchesco, particularmente del Martín Fierro, y los estudios que sobre el asunto nos dejó cuentan -y contarán siempre- entre las dilucidaciones más valiosas que sobre la materia existen. Cierto que hay errores de hecho, de interpretación y 
hasta de enfoque en sus disquisiciones, pero éstos no invalidan su magno y esclarecedor esfuerzo. Su edición crítica del poema no ha sido superada todavía hoy y es obra indispensable para todo el que se preocupe por la gauchología. Es indudable que se excedió en su afán de llegar a lo gauchesco a través de lo español, proclividad que ha disgustado particularmente a los "chauvinistas" argentinos, mas por lo menos este aspecto del Martín Fierro, o sea sus estrechas relaciones con la literatura española de los siglos clásicos, quedó definitivamente aclarado. Sólo por razones ajenas al sentido de justicia y a la crítica de espíritu imparcial puede silenciarse $u$ omitirse el nombre de Tiscornia en una recapitulación de los estudios de filologia gauchesca.

Manuel Pedro González, University of California, Los Angeles.

NOTAS

1 De mi vida y otras vidas por Baldomero Sanín Cano. Revista de América, Bogotá, 1949. 254 p.

2 Panorama de la cultura cubana, por Félix Lizaso. México, Fondo de Cultura Económica, 1949, 254 p.

3 Letras y hombres de Venèzuela por Arturo Uslar Pietri. México, Fondo de Cultura Económica, 1948, 175 p. 